\title{
Intravenous Ferric Carboxymaltose as Rescue Therapy in Severe Breath Holding Spells: A Case Report and Literature Review
}

\author{
Hee Jeong Yun, MD', Won Seop Kim, MD',2 Jon Soo Kim, MD' \\ ${ }^{1}$ Department of Pediatrics, Chungbuk National University Hospital, Cheongju, Korea \\ ${ }^{2}$ Department of Pediatrics, Chungbuk National University College of Medicine, Cheongju, Korea
}

Received: January 6, 2022

Revised: January 17, 2022

Accepted: January 19, 2022

Corresponding author:

Jon Soo Kim, MD

Department of Pediatrics,

Chungbuk National University

Hospital, 7761 sunhwan-ro,

Heungdeok-gu, Cheongju 28644,

Korea

Tel: +82-43-269-7342

Fax: +82-43-269-6064

E-mail: pedkjs79@naver.com
Breath-holding spells (BHSs) are non-epileptic, paroxysmal, behavioral, involuntary episodes frequently seen in childhood, occurring in up to $4.6 \%$ of otherwise healthy children aged 6 to 48 months [1]. They are usually triggered by emotional stimuli such as anger, frustration, fear, or injury. Dysregulation or instability of the autonomic nervous system and parasympathetic cardio-respiratory reflexes may represent possible evidence of BHS, but its precise pathogenic mechanisms remain incompletely understood $[2,3]$. BHSs may be categorized as cyanotic or pallid; the episodes last about 10 to 60 seconds and mostly spontaneously resolve [2]. Serious complications of BHSs are rare, but cases of sudden death, prolonged asystole, and status epilepticus have been reported [4]. Iron deficiency anemia (IDA) has been considered a risk factor for BHS in nearly $50 \%$ of children [1]. The effectiveness of oral iron supplementation in reducing the frequency and severity of breath-holding attacks is well-known $[5,6]$. Here, we describe the case of a 9-month-old girl who frequently experienced BHSs and received intravenous (IV) iron supplementation for her anoxic repetitive seizure attacks.

A 9-month-old developmentally normal girl visited the emergency room (ER) with a sei- zure-like event. The event was characterized by vigorous crying, after which she stopped crying and developed peri-oral cyanosis and tonic stiffening of the limbs and jerking for several minutes. Three weeks previously, she had a similar episode; she stopped being able to breathe after crying and then showed brief convulsive movements of the limbs and upward eyeball deviation without being aware of it. She was born at term via spontaneous vaginal delivery without any perinatal problems. Her birth weight was 3,360 g and she was breastfed. There was no family history of epilepsy or similar events. On examination, vital signs were normal and she had no focal neurologic deficits. Brain magnetic resonance imaging and electroencephalography results were normal. The laboratory findings were unremarkable, except for a hemoglobin $(\mathrm{Hb})$ level of $9.4 \mathrm{~g} / \mathrm{dL}$ and a mean corpuscular volume of 62.4 $\mathrm{fL}$. The patient was diagnosed with BHS and started on empirical oral iron supplements (5 $\mathrm{mg} / \mathrm{kg} /$ day of elemental iron).

One month later, she re-visited the ER with definite anoxic seizures after having bumped her head while falling. After the cessation of her excessive prolonged crying, she became cyanotic with desaturation and developed generalized tonic-clonic (GTC) seizures for 2 minutes with-

Copyright (C) 2022 Korean Child Neurology Society

This is an Open Access article distributed under the terms of the Creative Commons Attribution Non-Commercial License (http://creativecommons.org/licenses/by-nc/4.0/) which permits unrestricted non-commercial use, distribution, and reproduction in any medium, provided the original work is properly cited. 
out fever. The results of the IDA test at that time revealed microcytic hypochromic anemia: $\mathrm{Hb} 9.0 \mathrm{~g} / \mathrm{dL}$; total iron binding capacity (TIBC) $380 \mu \mathrm{g} / \mathrm{dL}$; ferritin $1.49 \mathrm{ng} / \mathrm{mL}$; and serum iron 17 $\mu \mathrm{g} / \mathrm{dL}$. Despite oral iron supplementation, she showed low levels of iron due to poor adherence. A few hours later, she experienced another seizure with the same semiology, which stopped after the administration of IV lorazepam $(0.1 \mathrm{mg} / \mathrm{kg})$. Even after admission, she had several GTC seizures lasting less than a minute with desaturation. She received IV anticonvulsants (phenobarbital and levetiracetam) but did not respond to these. Her parents were extremely worried and afraid.

To prevent these repeated anoxic seizures due to frequent spells, she received IV ferric carboxymaltose ( $150 \mathrm{mg} ; 15 \mathrm{mg} / \mathrm{kg}$ ) over the course of 15 minutes while monitoring her blood pressure, respiratory rate, heart rate and rhythm, and oxygen saturation. IV iron supplementation as rescue therapy was completed without any complications. Since then, the patient has had no more spells or seizures and returned to her condition prior to becoming sick. She was discharged with oral iron medications of a higher dosage $(10 \mathrm{mg} /$ $\mathrm{kg} /$ day of iron). In the next month, she had no events and her iron status returned to normal: $\mathrm{Hb}, 11.9 \mathrm{~g} / \mathrm{dL}$; TIBC, $349 \mu \mathrm{g} / \mathrm{dL}$; ferritin, $167.21 \mathrm{ng} / \mathrm{mL}$; and serum iron, $86 \mu \mathrm{g} / \mathrm{dL}$. She has now been event-free for 6 months and takes no more iron medications.

Our patient presented with severe BHSs, in the form of frequent spells of repetitive anoxic seizures with desaturation. She took oral iron to prevent these spells but responded poorly to it. As rescue treatment, we carefully administered a single dose of IV iron (ferric carboxymaltose) under intensive monitoring. The rescue treatment was successfully completed without any complications, and she experienced no further events. This case represents the first trial of single-dose IV iron supplementation for the rescue of repetitive seizures in children with severe BHSs.

According to their severity, BHSs can be divided into simple and complicated cases. Both types start with an emotional or painful physical stimulus; the simple type ends with a deep breath and crying, while complicated or severe spells generally end with loss of consciousness and a seizure-like tonic posture [1]. If apnea is prolonged, the child may develop myoclonic jerks or GTC seizures [1]. Episodes of unconsciousness and convulsions associated with BHSs that are short are usually harmless and should be treated by proper positioning to ensure a patent airway and prevent aspiration [2]. Although anti-seizure medications are not usually indicated in children with BHSs, these may stop the seizure activity, but do not prevent the spells themselves. Frequent BHSs with seizures cause parents to experience fear and anxiety and have a strong impact on the lifestyles of both the child and family. These children require prompt rescue.
Iron supplementation has been reported to substantially reduce BHSs in many studies [5,6]. Zehetner et al. [6] reported that iron supplementation (at $5 \mathrm{mg} / \mathrm{kg} /$ day of elemental iron for 16 weeks) significantly reduced the frequency of spells in 87 children (odds ratio, 76.48 ; $95 \%$ confidence interval, 15.65 to $373.72 ; P<0.0001$ ). In a recent meta-analysis of observational studies, the use of iron supplementation in subjects with BHSs who were iron-deficient reduced the frequency of BHS episodes, with an estimated $84 \%$ of children experiencing a $>50 \%$ reduction in episodes [5]. In a Turkish study, the comparison of responses to iron therapy among patients with and without anemia revealed that both spell burden and spell duration decreased in both groups, although these results were not statistically significant. The authors suggested that oral iron therapy should be given for all patients with BHSs, regardless of the presence of anemia [1]. The association between iron deficiency and BHSs is not fully understood. It has been suggested that iron, particularly in the brain, plays a key role in neuronal and glial energy metabolism, as well as neurotransmission (e.g., catecholamine metabolism) [5].

Although oral iron is the standard initial therapy for IDA in both children and adults, many patients fail to respond due to poor adherence, inadequate absorption, adverse effects, and/or failure to correct the primary etiology [7]. In addition, as in our case, there may be many clinical situations where the administration of high concentrations of iron is rapidly required. Despite safety concerns, high costs, and the need for "off-label" use, treatment strategies using parenteral iron in pediatric populations are gradually increasing [7-10]. Ferric carboxymaltose is a relatively new IV iron preparation with demonstrated safety and efficacy in adults with IDA [7]. Ferric carboxymaltose can be administered in 15 minutes without a previous test dose and has a much shorter infusion time than most other formulations of IV iron. Given its favorable safety profile and the ease of its administration in adults, it is being tested for off-label use in children with various clinical situations, such as irritable bowel disease, heavy menstrual bleeding, nutritional disorder, or restless sleep disorder (Table 1).

The correction of iron deficiency is crucial in children with BHSs, regardless of the presence of anemia. In many pediatric studies, IV iron showed excellent safety and efficacy. In children with severe BHSs, IV iron supplementation as a rescue treatment should be considered for improving acute symptoms such as frequent spells and/or repetitive seizures.

This study was performed in accordance with the Declaration of Helsinki and was approved by the Institutional Review Board of Chungbuk National University Hospital (2020-06-026). Written informed consent by the patients was waived due to a retrospective nature of our study. 
Table 1. Pediatric studies of intravenous ferric carboxymaltose for the correction of iron deficiency anemia

\begin{tabular}{|c|c|c|c|c|}
\hline & Primary etiologies & Patients (age) & Efficacy & Safety \\
\hline Powers et al. [9] (2015) & $\begin{array}{l}\text { Heavy menstrual bleeding (38\%), } \\
\text { nutritional }(24 \%) \text {, GI bleeding } \\
\text { and/or malabsorption }(20 \%)\end{array}$ & 87 (0.8-20.8 years) & $\begin{array}{l}\text { Median increase; } \mathrm{Hb} 3.3 \mathrm{~g} / \mathrm{dL} \\
\text { (1-30 weeks) }\end{array}$ & $\begin{array}{l}\text { Generalized urticarial/pruritis } \\
(6 \%) \text {, nausea/vomiting (3\%) dys- } \\
\text { pnea (1\%), extravasation (1\%) }\end{array}$ \\
\hline Tan et al. [8] (2017) & $\begin{array}{l}\text { IBD }(80 \%) \text {, dietary insufficiency } \\
(10 \%) \text {, parenteral nutrition (8\%) }\end{array}$ & 51 (1-13 years) & $\begin{array}{l}\text { Median increase; } \mathrm{Hb} 2.7 \mathrm{~g} / \mathrm{dL} \text {, } \\
\text { serum iron } 6.6 \mu \mathrm{mol} / \mathrm{L}\end{array}$ & None \\
\hline Powers et al. [7] (2017) & $\begin{array}{l}\text { Heavy menstrual bleeding (57\%), } \\
\text { nutritional (36\%), GI bleeding } \\
(24 \%), \text { IBD }(17 \%)\end{array}$ & 116 (0.8-18 years) & $\begin{array}{l}\text { Median increase; } \mathrm{Hb} 3.2 \mathrm{~g} / \mathrm{dL} \\
\quad(4-12 \text { weeks) }\end{array}$ & $\begin{array}{l}\text { Urticaria/pruritis (3\%), dyspnea } \\
(1 \%) \text {, tingling (1\%), extravasa- } \\
\text { tion (1\%) }\end{array}$ \\
\hline DelRosso et al. [10] (2020) & Restless sleep disorder (100\%) & 15 (5-18 years) & $\begin{array}{l}\text { Much improved CGI scale and } \\
\text { iron parameters }\end{array}$ & Syncope (7\%), \\
\hline
\end{tabular}

GI, gastrointestinal; IBD, inflammatory bowel disease; Hb, hemoglobin; ID, iron deficiency; IDA, iron deficiency anemia; CGI, clinical global impression.

\section{Conflicts of interest}

No potential conflict of interest relevant to this article was reported.

\section{ORCID}

Hee Jeong Yun, https://orcid.org/0000-0002-1171-8347

Won Seop Kim, https:/ / orcid.org/0000-0003-4541-7902

Jon Soo Kim, https://orcid.org/0000-0003-2586-1942

\section{Author contribution}

Conceptualization: JSK. Data curation: HJY. Formal analysis: WSK. Funding acquisition: WSK. Methodology: WSK. Project administration: JSK. Writing-original draft: HJY. Writing-review \& editing: JSK.

\section{References}

1. Gurbuz G, Perk P, Cokyaman T, Gurbuz OB. Iron supplementation should be given in breath-holding spells regardless of anemia. TurkJ Med Sci 2019;49:230-7.

2. Rathore G, Larsen P, Fernandez C, Parakh M. Diverse presentation of breath holding spells: two case reports with literature review. Case Rep Neurol Med 2013;2013:603190.

3. Tomoum H, Habeeb N, Elagouza I, Mobarez H. Paediatric breath-holding spells are associated with autonomic dysfunction and iron deficiency may play a role. Acta Paediatr 2018; 107:653-7.

4. Moorjani BI, Rothner AD, Kotagal P. Breath-holding spells and prolonged seizures. Ann Neurol 1995;38:512-3.

5. Hecht EM, Layton MR, Abrams GA. Iron supplementation for the treatment of breath-holding spells: a systematic review and meta-analysis. Clin Pediatr (Phila) 2020;59:819-22.

6. Zehetner AA, Orr N, Buckmaster A, Williams K, Wheeler DM. Iron supplementation for breath-holding attacks in children. Cochrane Database Syst Rev 2010;5:CD008132.

7. Powers JM, Shamoun M, McCavit TL, Adix L, Buchanan GR. Intravenous ferric carboxymaltose in children with iron deficiency anemia who respond poorly to oral iron. J Pediatr 2017; 180:212-6.

8. Tan ML, Windscheif PM, Thornton G, et al. Retrospective review of effectiveness and safety of intravenous ferric carboxymaltose given to children with iron deficiency anaemia in one UK tertiary centre. Eur J Pediatr 2017;176:1419-23.

9. Powers JM, Shamoun M, McCavit TL, Buchanan GR. Efficacy and safety of ferric carboxymaltose in children with iron deficiency anemia not responsive to oral iron therapy. Pediatr Blood Cancer 2015;62(Suppl 2):S38.

10. DelRosso LM, Picchietti DL, Ferri R. Comparison between oral ferrous sulfate and intravenous ferric carboxymaltose in children with restless sleep disorder (RSD). Sleep 2021;44: zsaa155. 